\title{
Total Run-Out Measurement OF THE Multistart Worm by THE LaSer Line Triangulation SenSOR
}

\author{
Alexander Prošek \\ VÚTS, a.s., Measurement Department, \\ Svárovská 619, Liberec XI - Růžodol I, 46001 Liberec, Czech Republic \\ e-mail: alexander.prosek@vuts.cz
}

\begin{abstract}
This article describes a total run-out measurement of a multistart worm which is pressed on a rotor shaft of an electric motor. The measurement is realized by a laser line triangulation sensor during the motor's running. The total run-out evaluation is executed for each spiral of the worm on its addendum circle along the whole length of the worm.
\end{abstract}

\section{Keywords}

Total run-out; Laser line triangulation sensor; Multistart worm.

\section{Introduction}

Measuring total run-out by a mechanical gauge is difficult because the addendum cylinder of the worm is not continuous and this approach requires tracing the worm outer surface during its rotation. Moreover, it is not possible to maintain a constant speed of the rotor in our case. On the other hand, the optical measurement by laser triangulation is simple to apply.

It is supposed that the rotor shaft rotation axis is identical to the motor housing axis. The datum is on the housing mounting region cylindrical surface (Figure 1). If this assumption is violated, then the whole shaft can lie out of the tolerance range related to the datum surface due to axes misalignment but the rotor does not run-out relative to its rotation axis. The rotor position is variable relative to the motor body and the previous condition ensures the axis symmetry with respect to datum axis. This condition is justified for any other measurement method and it is caused by the fact that the rotor is movable relative to the datum.

Another advantage of the optical method is the absence of a contact between the measured part and the gauge, and thus the measured part is protected from damage. On the other hand, this method is sensitive to optical conditions; these issues are discussed later.

\section{$1 \quad$ Measurement Equipment}

The motor is set in a V-block which ensures an accurate motor positioning relative to the sensor. The motor is mounted by prism on the datum surfaces which are defined by the geometrical tolerance. The profilometer is set in the accurately defined position relative to the supposed axis of the reference cylinder surface. The sensor is not set directly against the supposed shaft axis but it is slightly shifted in order to eliminate the specular reflection of the laser light that can reach the profilometer CMOS sensor. A precise calibration specimen with the same geometry on the significant surfaces as the real motor was manufactured. This calibration specimen should be a tool for finding a trend in data which is caused by the inaccurate assembly of the measurement equipment. This trend is used for the data calibration during the measurement. A scheme of the measurement geometrical conditions is shown in Figure 1. 
The profilometer measures the distance of the worm profile from its reference surface. One sample of profile data is a vector of the 2D points of coordinates which are related to reference surfaces of the sensor. These coordinates are measured directly in micrometres. The sensor is used in a stream mode, i.e. the profiles are acquired continuously one by one. A profilometer TLE1 with measurement range $35-65 \mathrm{~mm}$ produced by the Metralight company was selected for the measurement.

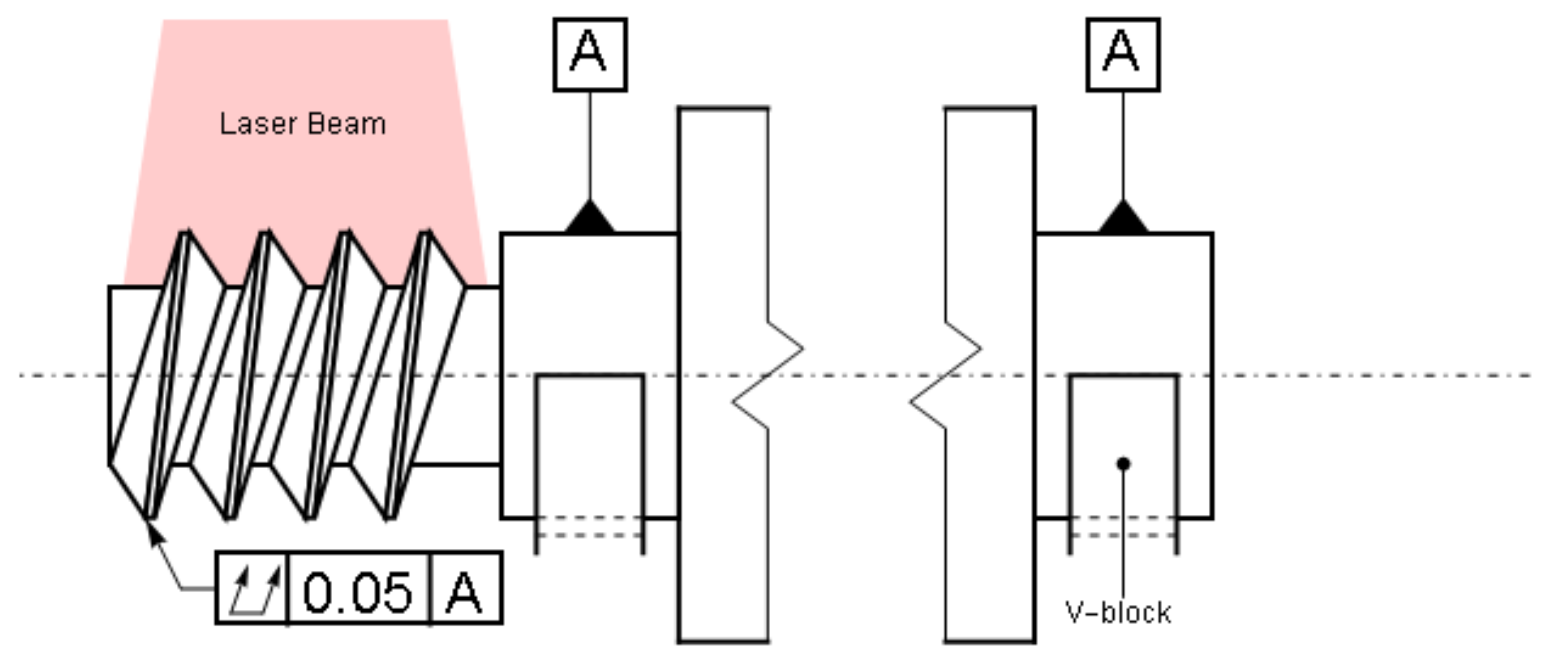

Source: Own

Fig. 1: Measurement scheme

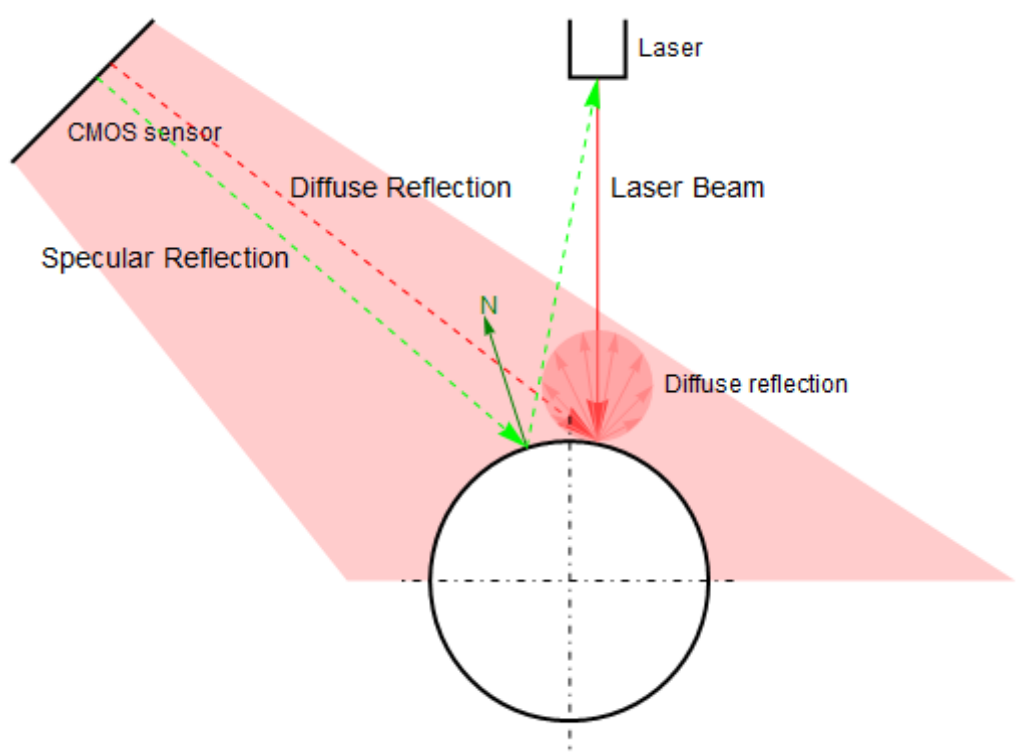

Source: Own

Fig. 2: Laser line triangulation sensor principle - The image shows both types of reflections which are visible on the shiny cylinder surface (diffuse reflection and unwanted specular reflection, $N$ is the surface normal). 

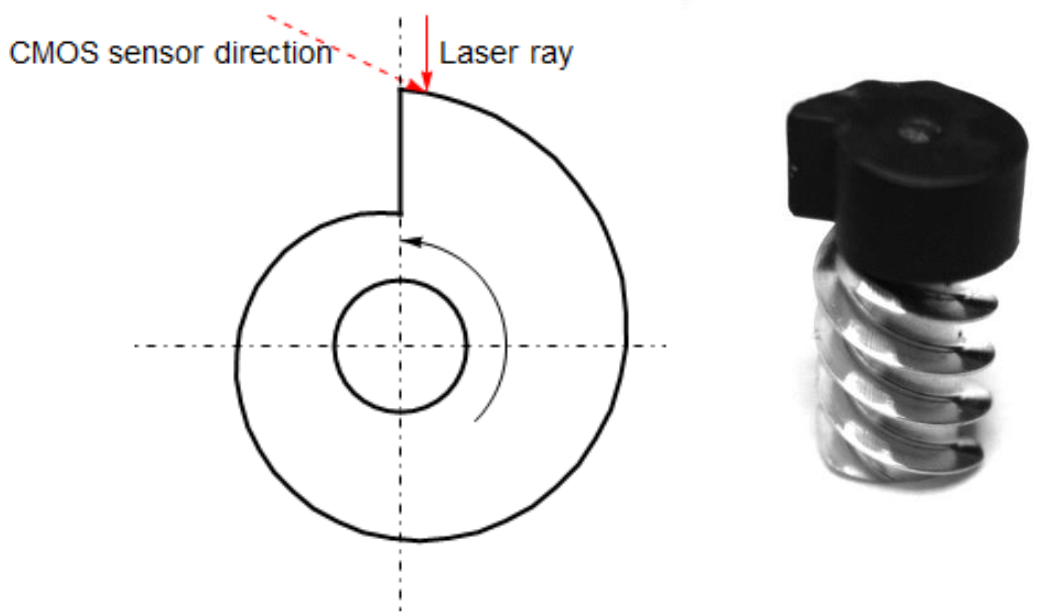

Source: Own

Fig. 3: Spiral part-The part placement on the worm is shown on the right.

\section{$2 \quad$ Measurement}

The motor with a worm (pressed on the rotor shaft) is connected to power supply, and rotor revolutions are controlled by voltage level. The voltage is set to a value that ensures as a stable and low speed as possible. It is necessary to detect the rotor shaft rotation angle during the measurement. A special plastic part, which is attached on the shaft end by a magnet, is used for this purpose. This part has a variable radial displacement along the rotation angle so there is a unique value of displacement for each shaft rotation angle (see Figure 3).

Whole angle range $(0,360)$ degrees are split into disjointed circular sectors with an angle of 5 degrees. The length range along the shaft axis was split into sectors of $0.5 \mathrm{~mm}$ width (these parameters are variable). This division creates a 2D bins array of the measurement area. The measurement is executed for several revolutions. The spiral part displacement is detected for each profile. This value is intended for the profiles sorting by the rotation angle into angle bins. When the measurement is finished, each profile set relative to specified circular sector is evaluated by statistical methods. This is discussed later in section 2.2.

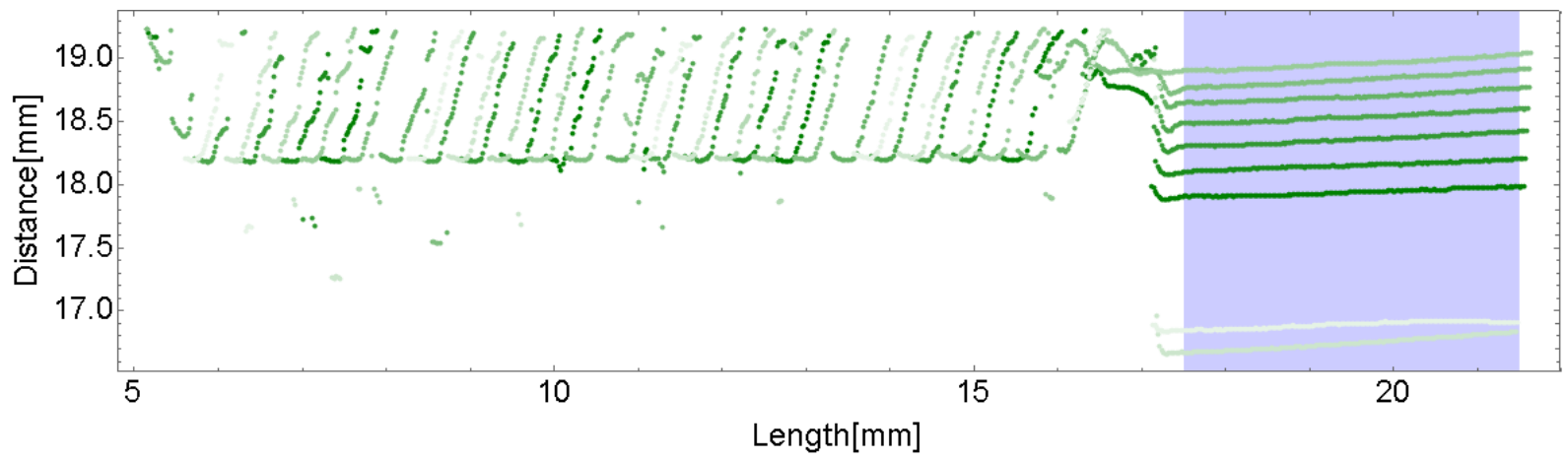

Source: Own

Fig. 4: Record of ten successive profiles-attached spiral part is in the light blue region

\subsection{Measurement Settings}

Maximum frame rate of the used sensor is about 30 frames per second (depending on exposure time, but the readout time of the used CMOS chip is $33.34 \mathrm{~ms}$ ). The lowest motor revolutions that can be used are about 4 revolutions per second so it is not possible to obtain more than nine frames per revolution with the full frame readout. The selected profilometer TLE1 supports quite a variable region of interest (ROI) settings that allows setting ROI close to the watched edge neighborhood. It is necessary to set short exposure time to achieve the 
maximum frame rate. Additionally, it is necessary to set high laser power and CMOS sensor gain due to low light diffusion of the shiny metal surface.

It is necessary to repeat the measurement for several revolutions because of the low frame rate per one revolution. However, a case when a ratio of the frame rate and revolutions number is integer can occur. Then, the same places are observed and the other places are skipped during two successive revolutions. Some angle bins remain empty in this case. This problem is solved by checking points count in the bins array. This can be simply solved by changing the sensor frame rate which can be achieved by enlarging ROI over more CMOS sensor rows. This causes the CMOS sensor readout time increase.

The first step of the measurement is the spiral part mapping. The sensor ROI is set to the possible smallest region that covers the decreasing surface of this part. This allows us to scan the surface with approximately a two degrees' step. This map is used to detect the shaft rotation angle. Linear interpolation over this map is used for the shaft angle detection during the measurement.

There are several other issues with optical properties of the observed surface which influence setting of the measurement. As mentioned above, the sensor is not placed against the shaft axis directly but it is slightly shifted behind the axis (shown in Figure 2). The measurement principle of the laser line triangulation sensor is based on capturing an image of the laser light diffused on the target surface. The worm is made of a ground metal and the biggest part of the laser light is specular reflected. The first problem is to avoid the laser light reflection into the CMOS sensor. This is partially solved by the sensor shift out of the shaft axis plane. However, two reflection lines on the shaft surface still exist (see Figure 2). The first is diffused light on the surface and the second is specular reflection. Specular reflection in the sensor direction is caused by the fact that there is always a point on the shaft cylindrical surface where the laser light is reflected into sensor according the Snell's law. It is necessary to choose a geometrical arrangement of the measurement equipment so that these two phenomena remain separated.

The evaluation is also complicated by secondary specular reflections between the thread faces (see Figure 6). Although these reflections are not visible on the addendum cylindrical surface of the profilometer, which evaluates light intensity over the each CMOS sensor row separately, the secondary reflection on the face can be chosen instead of the diffuse reflection on the addendum. This sensor behavior cannot be simply eliminated so it is necessary to carefully select those parts of the profile which really represent the thread addendum during the data processing.

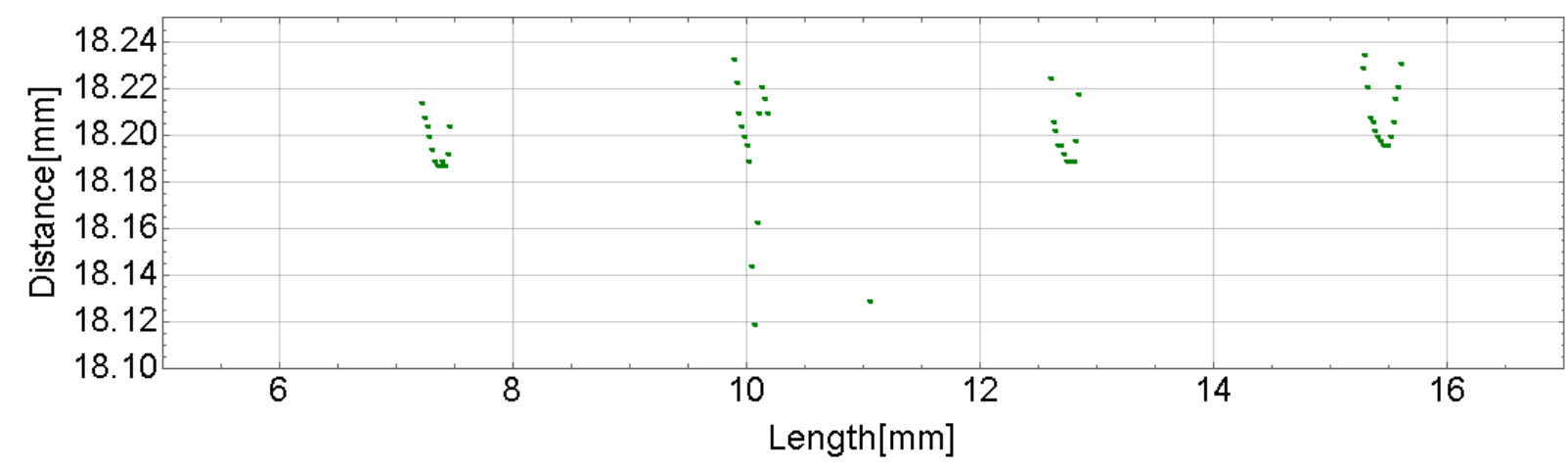

Source: Own

Fig. 5: Worm profile detail - several outlying points caused by dirt on thread surface visible on second thread from left 


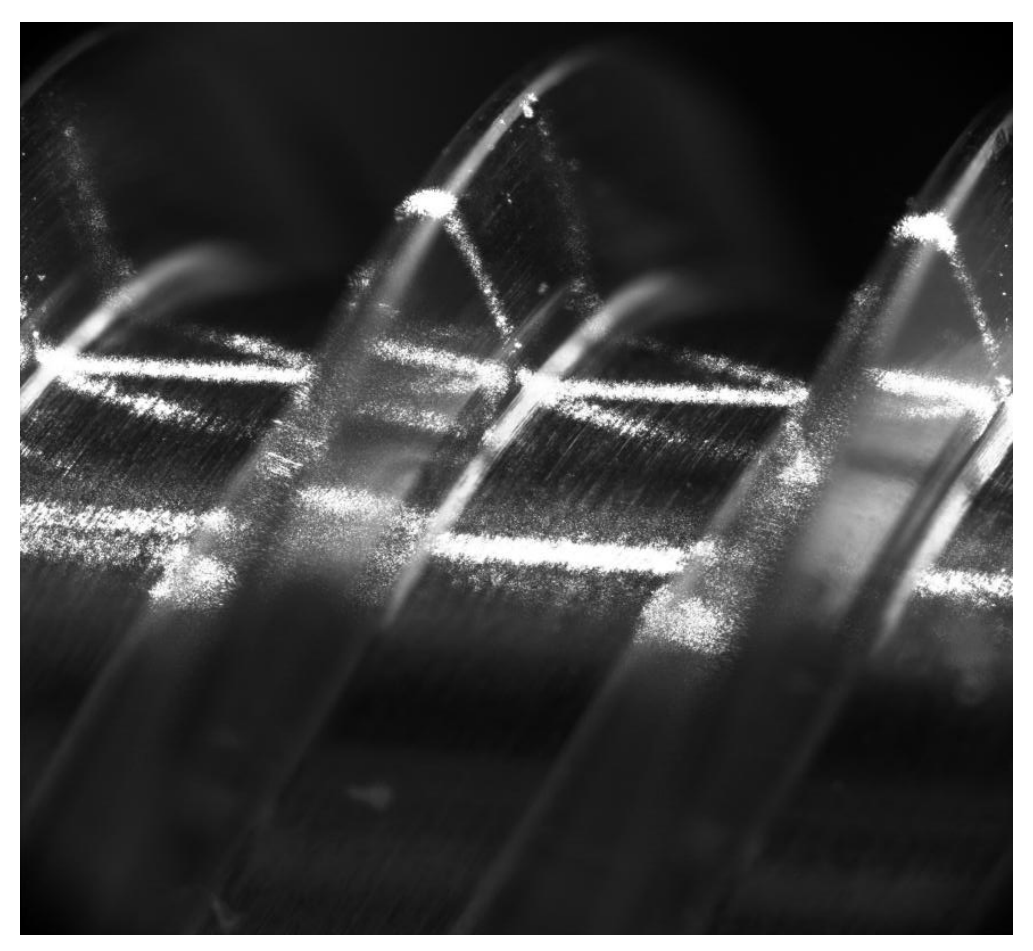

Source: Own

Fig. 6: Detail of the worm with visible multiple reflections of the laser beam between thread faces. The thickest horizontal line is specular reflection which is drawn in Figure 2 by green arrows (image was acquired by camera with macro lens - it is not an image acquired by used profilometer).

Moreover, the measurement data can be influenced by the CMOS rolling shutter effect. This effect is more significant for higher rotation speed. The CMOS chip rows are exposed with a short time delay. The rotor is slightly turned about its axis during this delay so the profile scan does not correspond with the unique angle. The profile continuously crosses the short angle range which is determined by the time delay between the first and the last exposed row. It was possible to reach a sufficiently low speed in our case so this effect can be ignored. Generally, this effect can be totally eliminated by using a chip with a global shutter.

\subsection{Evaluation}

A rotation angle is determined for each obtained profile. Points on the addendum circle are found then. Each upper thread edge is replaced by one delegate point. These points are sorted into a $2 \mathrm{D}$ bin array according to its angle and $x$-coordinate.

Precise data processing is necessary due to high sensitivity of the measurement method on the optical conditions which were described in the previous section. Under specific conditions, which cannot be surely eliminated, problematic places (e.g. scratches, grease or other dirt) are scanned periodically. These faulty values undesirably influence the used statistics. Hence, if the data condition for the expected shape or continuity were violated, then the point was rather dropped.

Values from each bin are replaced by median and these values are considered as a distance map result. This result is shown in Figure 7. Diagonal strips represent the real measured data and the transparent part of the plot is only an interpolation for better visualization. In Figure 8, the same result is mapped on a 3D cylindrical surface. 
The total run-out is approximately equal to a difference between the global maximum and minimum on this distance map. A real total run-out is slightly different due to geometrical conditions of the measurement since the profile is observed from behind the worm axis (Figure 2).

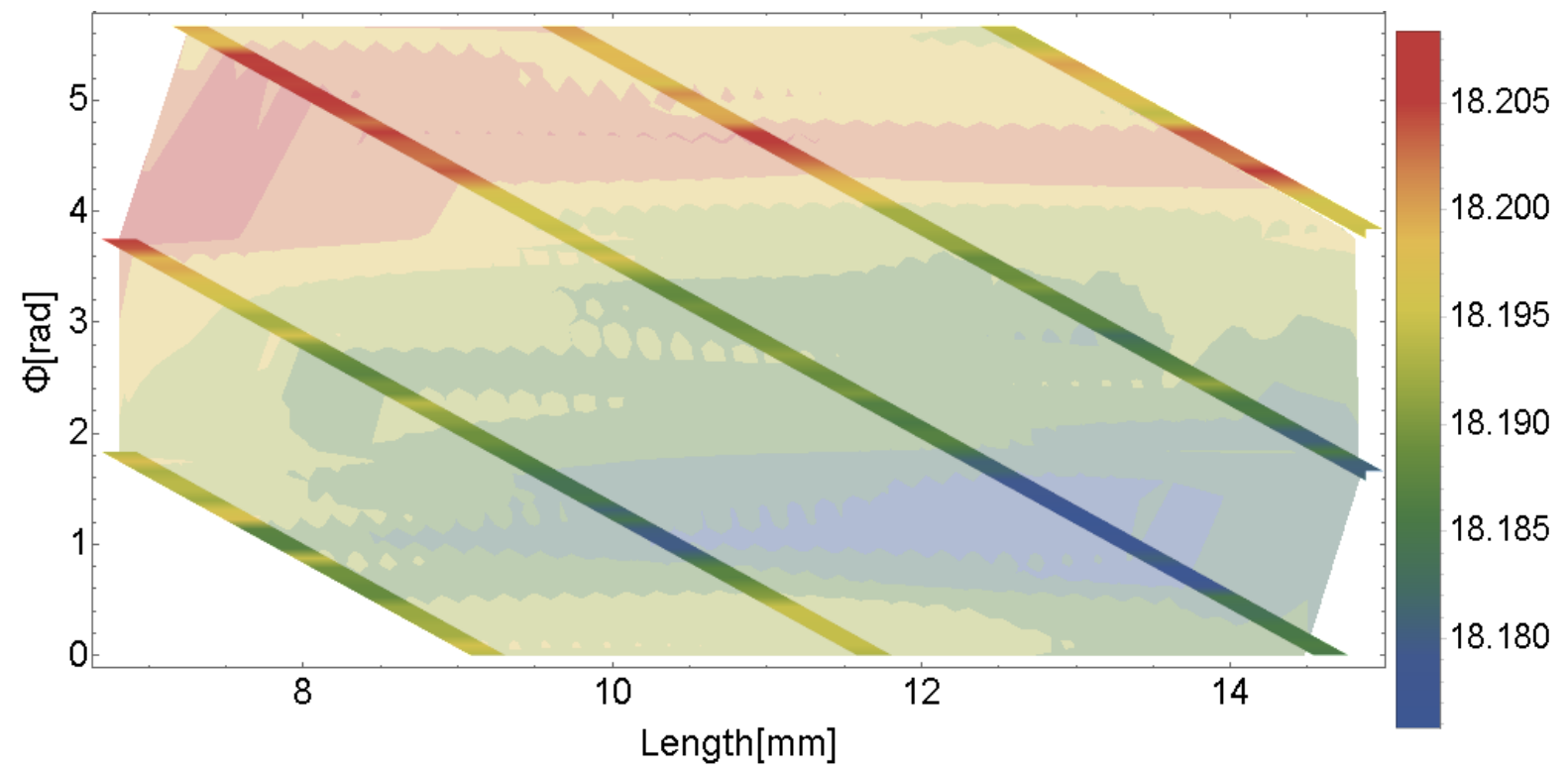

Source: Own

Fig. 7: Distance map - Strips represent the real measured points, an area between the strips is interpolated for better visualization of the distance layout over the outer cylinder.

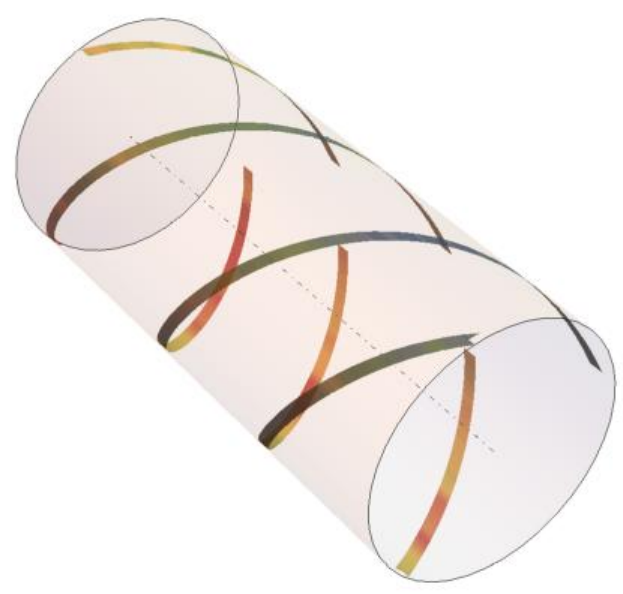

Source: Own

Fig. 8: Distance map mapped on the outer cylinder of the worm

\section{Conclusion}

The total run-out measurement based on laser triangulation is simply applicable. The measurement is executed during the motor operation and there is no need for any other measurement equipment than the laser profilometer. In our case, it was not possible to run a motor with a low enough speed that allowed us to capture enough profiles for just one revolution. Hence, a special spiral part was used to observe the shaft rotation angle and the results were evaluated for several successive revolutions. 
Although the measurement by the laser profilometer can be simply realized, there are some issues based on the optical conditions. These problems were solved by precise setting of the profilometer and careful data processing. The used method provides stable and repeatable results.

Part of the data processing is executed by the sensor itself. This approach can be restrictive because the image information obtained by the CMOS sensor is lost. An alternative approach that can provide a more flexible evaluation is processing the whole image data. For example, specular reflection can be detected from the knowledge of geometry and erased from the image. But the selected sensor does not provide sufficient data transfer for the image data streaming.

Alternatively, the measurement can be executed without the spiral part because the worm thread can also be used for the rotation detection. But the spiral part is more convenient because the worm can contain more helices and it is necessary to distinguish them for the correct angle detection.

\section{Literature}

[1] TLE1 Sensor. Technical specification (rev. G), sensor firmware: 111 3v2 [online], available from: http://www.metralight.com/products/doc/tle1/tle1_ug_g.pdf

[2] CHEN, F; BROWN, G. M.; SONG, M.: Overview of 3-D shape measurement using optical methods. Optical Engineering. 2000, Vol. 39, Issue 1. DOI: 10.1117/1.602438

[3] VÁRADY, T.; MARTIN, R. R.; COX, J.: Reverse engineering of geometric models an introduction. Computer-Aided Design. 1997, Vol. 29, Issue 4, pp. 255-268. DOI: $\underline{10.1016 / \mathrm{S} 0010-4485(96) 00054-1}$

[4] MIKULSKI, S.: Laser triangulation in three-dimensional scanners. Computer Application in Electrical Engineering. 2013, Vol. 11, pp. 485-491. All volumes are available from WWW: http://www.iee.put.poznan.pl/wydawnictwa

Ing. Alexander Prošek 


\section{MĚŘENÍ CELKOVÉHO HÁZENÍ VÍCECHODÉHO ŠNEKOVÉHO PASTORKU POMOCÍ LASEROVÉHO TRIANGULAČNÍHO SNÍMAČE}

Tento článek popisuje měření vícechodého šnekového pastorku nalisovaného na hřídeli rotoru elektrického motoru. Měření realizováno pomocí laserového triangulačního snímače za běhu motoru. Vyhodnocení celkového házení je provedeno pro každý závit šneku na jeho vnější kružnici po celé délce šneku.

\section{MESSUNG DER GESAMTEN LAUFABWEICHUNG DES MEHRGÄNGIGEN SCHNECKENRITZELS MIT HILFE EINES LASERTRIANGULATIONSSENSORS}

Dieser Artikel beschreibt die Messung des mehrgängigen Schneckenritzels, welche auf die Rotorwelle eines Elektromotors gepresst ist. Die Messung wurde mit Hilfe eines Lasertriangulationssensors durchgeführt, während der Motor lief. Die Auswertung der Laufabweichung wird für jede Windung der Schnecke auf ihrer äußeren Kreisbahn über die gesamte Länge der Schnecke durchgeführt.

\section{POMIAR OGÓLNYCH DRGAŃ ŚLIMAKOWEGO KOŁA ZĘBATEGO PRZY POMOCY LASEROWEGO CZUJNIKA TRIANGULACYJNEGO}

W niniejszym artykule opisano pomiar ślimakowego koła zębatego umieszczonego na wale wirnika silnika elektrycznego. Pomiaru dokonywano przy pomocy laserowego czujnika triangulacyjnego w czasie pracy silnika. Ogólne drgania badano dla każdego gwintu ślimaka na jego zewnętrznym kole na całej długości ślimaka. 